\title{
Em busca de significados perdidos: convenções da ópera veneziana do Seiscentos
}

Silvana Scarinci e Laura Rónai

Resumo: Este ensaio pretende expor as principais convenções da música vocal operística da primeira metade do século XVII e algumas das construções poéticomusicais que as sustentam. Para o cantor (ou intérprete de baixo-contínuo) interessado na execução deste repertório, a reflexão sobre estas questões proporcionará performance mais culta e historicamente informada, resgatando um conhecimento comum ao homem letrado da época, perdido para a maior parte dos músicos modernos.

Palavras-chave: convenções da ópera; música veneziana do século XVII; interpretação historicamente orientada.

\section{IN SEARCH OF LOST MEANINGS: 17TH CENTURY VENETIAN OPERA CONVENTIONS}

Abstract: This essay seeks to explain the main conventions of vocal operatic music from the first half of the seventeenth century and some of the poetic and musical structures that support them. For the singer (or the figured bass interpreter) interested in the execution of this repertoire, reflection on these issues will provide for a subtler, more historically informed performance, rescuing a knowledge that was common to the educated man of the time, but has since been lost to most modern players.

Keywords: Opera Conventions; 17th Century Venetian Music; Historically Informed Performance. 
Apesar de não ter nascido em Veneza, a ópera encontrou na República Sereníssima solo fecundo para seu florescimento e para a fixação de diversas convenções que perduraram na história do gênero. Com a abertura dos teatros públicos de ópera na cidade, o jovem espetáculo ganhava uma audiência regular, que uma vez acostumada com as extravagâncias do carnaval, passava a sustentar as novidades e experimentações do novo gênero híbrido. De 1637 a 1678, os venezianos assistiram a mais de 150 óperas em nada menos do que nove teatros diferentes. A proliferação do gênero exigiu que a produção fosse contínua e plena de novidades. Desta maneira, criaram-se convenções, ou cenas-padrão que podiam ser compostas com certa velocidade, tornando-se parte da expectativa do novo público pagante. Nasceu assim a cena de loucura, o dueto de amor, a cena de lamento - em geral feminino - e a cena de encantamento mágico.

Estas convenções se estabelecem pouco a pouco com o desenvolvimento do gênero dramático-musical recém criado à medida que novas obras são produzidas nos teatros de ópera venezianos e certos experimentos são acolhidos ou rejeitados - pelo novo público pagante, estabelecendo assim padrões ou modelos para compositores subsequentes. Para que possamos compreender tais convenções, devemos por um lado nos debruçar sobre a história da literatura e do teatro italianos, e por outro, sobre os estudos específicos dos libretos e das publicações que proliferavam na época, possibilitando o acesso a um corpus de parafernália teórica que revela significados históricos há muito tempo esquecidos por intérpretes mais modernos. Toda a discussão teórica produzida em Veneza no século XVII foi reproduzida nos libretos publicados como uma espécie de "lembrança” das óperas após suas apresentações; além dos libretos, surgia na época uma forma de proto-propaganda dos espetáculos, panfletos divulgados antes da temporada de uma determinada ópera, conhecidos como Scenario. Estes folhetos - em geral contendo de 20 a 30 páginas - apresentavam uma sinopse do drama, assim como a transcrição de seu libreto completo. De grande interesse para os estudiosos de ópera e intérpretes modernos são os prefácios destes Scenari que documentam profusamente as preocupações estéticas e as ansiedades em 
relação a um gênero que ainda lutava para se estabelecer. Um destes panfletos, datado de 1641, de autoria do conhecido poeta Giulio Strozzi, permite-nos entrever um momento marcante na história da recepção musical: o surgimento das primeiras cantoras virtuoses - as prima donne - que aos poucos estabeleceram uma relação até então inaudita entre intérpretes e público, em que o cantor ganhava primazia nas hierarquias do espetáculo, tornando as obras e seus autores secundários aos olhos de um público ávido por virtuosismo vocal:

Supera a pobreza de minhas idéias o tesouro da Música do Sig. Francesco Sacrati Parmigiano, o qual, maravilhosamente soube com suas harmonias adornar os meus versos e com a mesma maravilha pode ainda conjugar um nobilíssimo coro com tantos sofisticadíssimos Cisnes da Itália; e do Tibre da mais rigorosa e terrível estação, trouxe ao Adriático uma suavíssima Sereia que docemente sequestra as almas e deleita os olhos e os ouvidos dos espectadores. Pela diligência, do Sig. Sacrati, deve reconhecer a Cidade de Veneza os favores da virtuosíssima Signora ANNA. ${ }^{1}$

Anna Renzi criou um modelo de cantora que não perduraria por muito tempo. Se as primeiras cantoras de ópera sobrepunham sua profissão com a das atrizes, a maioria delas advindas das trupes de Commedia del'Arte, com Anna Renzi se dá a separação das águas, apesar de a cantora manter a reputação de excelente atriz.

Até meados dos anos 1640, imperava o recitativo como recurso musical mais expressivo e eficaz para imitar a fala em música, o parlare cantando. Os versos apropriados para o recitativo eram os versi sciolti, de sete e onze sílabas (settenari e endecassilabi respectivamente), livres de rimas, e propícios à imitação da fala em função da irregularidade de seus acentos internos. Com a "descoberta" do recitativo, nasce concomitantemente o baixo-contínuo apropriado para sustentar e enfatizar o caráter livre e mais prosaico de tais versos. Deste modo, o

\footnotetext{
1 ... Supplisce alla povertà de' miei concetti il tesoro della Musica del Sig. Francesco Sacrati Parmigiano, il quale maravigliosamente hà saputo com le sue armonie adornar i miei versi e con la stessa meraviglia hà potuto ancora metter insieme un nobilíssimo Choro di tanti esquisitissimi Cigni d'Italia; e sin dal Tebro nel maggior rigor d'un' horrida stagione hà condotta sù l'Adria una suavissima Sirena, che dolcemente rapisce gli animi, \& alletta gli occhi, e l'orecchie degli ascoltanti. Dalla diligenza del Sig. Sacrati deve riconoscere la Città di Venetia il favore della virtuosíssima Signora ANNA. Argomento, e scenario della Finta Pazza. (Apud Rosand, 1991, p.94)
} 
nascimento da ópera se vincula visceralmente ao gênero dramático, expresso e mantido pela onipresença da palavra, da qual luta por não se separar, já que poria em risco os princípios de verossimilhança tão caros aos teóricos, compositores e poetas seiscentistas, criadores do drama per musica. Anna Renzi, portanto, afiliava-se ao estilo florentino, sendo cantora hábil na elocução retórica da palavra cantada, qualidade que pouco a pouco perderia espaço com a ascensão da ária em detrimento cada vez maior da força expressiva do recitativo. Testemunho do gosto que imperava no início do século XVII, as palavras de um autor anônimo do tratado // corago (1630) nos expõe mais claramente as relações íntimas entre o teatro falado e o cantado, o ator e o cantor, as relações de verossimilhança da fala - recitativo - para personagens "de carne e osso" e do canto - ária - para personagens mitológicas:

Sobretudo, para ser um bom orador cantando é necessário ser também um bom orador falando, quando vimos que algumas pessoas que tinham graça particular ao recitar, fizeram maravilhas quando ao mesmo tempo sabiam também cantar. Em relação a isto, alguns questionaram se devemos preferir um músico não ruim que seja um orador perfeito ou um músico excelente, mas com pouco ou nenhum talento para recitar, pelo que se pode perceber, que sim, da mesma forma como para poucos conhecedores de música agradaram mais os excelentes cantores embora frios no recitar, enquanto que, para o público comum do teatro, este obteve maior satisfação com os atores perfeitos com voz e perícia musical medíocres. Devendo, portanto o músico distribuir os papéis de maneira adequada, e se servir de todos à perfeição, tentando na medida do possível, imitar os excelentes cantores, mas atribuindo, àqueles exangues e mais velhos, partes que não exijam muita atuação e colocando muitos elementos [cênicos] a seu redor, pondo-os em nuvens e outras máquinas aéreas, onde não se requer tanto movimento, nem expressão de atitudes histriônica.

Para começar com os personagens ou interlocutores para quem a representação musical parece mais apropriadamente convir, são muito adequados para as ações profanas, as divindades antigas como Apolo, Teti, Netuno e outros deuses estimados, como também os semideuses e heróis vetustos, entre os quais se pode elencar principalmente os rios, lagos, e em especial os mais célebres entre as musas, como Peneu, o Tibre, o Trasimeno e sobretudo, aqueles personagens que consideramos terem sido músicos perfeitos, como Orfeu, Anfion e similares. A razão de tudo isto é que todos 
os ouvintes sabem perfeitamente que, ao menos nas partes mais conhecidas da terra, pessoas ordinárias não falam cantando, mas simplesmente falam; é mais facilmente aceito o conceito do falar cantando para personagens sobrehumanos do que esta manifestação nos homens comuns, pois sendo o discursar harmônico mais elevado, mais magistral, mais doce e nobre do que o falar ordinário, por uma tendência inata considera-se que estes personagens possuem dose maior do sublime e do divino. ${ }^{2}$

Este último parágrafo é especialmente instigante, pois ao olharmos para trás, no que tange música e teatro, imaginamos que a plateia de antigamente era feita de pessoas extremamente diferentes de nossas plateias de hoje. Uma das razões mais frequentemente citadas pelos músicos que se recusam a incorporar às suas execuções os hábitos específicos característicos de outra época é a de que o público mudou, e, portanto as plateias de hoje simplesmente não poderiam compreender as convenções do passado. Por isso mesmo, é muito interessante perceber que as questões que nos preocupam hoje encontravam eco há 400 anos; e que a famosa "suspension of disbelief", que se requer hoje de qualquer ouvinte de ópera ou musical, de qualquer espectador de teatro dramático ou cinema já

\footnotetext{
${ }^{2}$ Sopra tutto per essere buon recitante cantando bisognerebbe esser anche buono recitante parlando, onde aviamo veduto che alcuni che hanno avuto particolar grazia in recitare hanno fatto meraviglie quando insieme hanno saputo cantare. Intorno a che alcuni muovono questione se si deva ellegere un musico non cattivo che sai perfetto recitante o pure un musico eccelente ma di poco o nessum talento di recitare, nel che si è toccato con mano che sì come ad alcuni pochi molto intendenti di musica sono più piaciuti l'eccelenti cantori quantunque freddi nel recitamento, così al co[um]ne del teatro sodisfazione maggiore hanno dato i perfetti istrioni con medíocre voce e perizia musicale. Pertanto dovendo il musico distribuire a proposito le parti e servisi di tutti a perfezione, procurerà per quanto si mostrerà possibile di imitar le eccelenti cantori ma [mettendo quelli] esangui et in età nel recitare in parti che non siano molto attuosi e che abbino molti ornamenti a torno come in nuvole et altre machine per aria dove non si richiede tanto moto né espressione di atteggiamenti istrionici.
}

Per cominciare da personaggi o interloquitori che la rappresentazione armonica pare che più convenevolmente abbracci, sembrano molto a proposito per le azioni profane le deità antiche come Apollo, Teti, Nettuno et altri stimati numi, con anche i semidei et eroi vetusti, massime tra i quali si possono annoverare i fiumi, laghi, massime i più celebri appresso le muse come Peneo, il Tebro, il Trasimeno e sopra tutti quei personaggi che stimiamo essere stati perfetti musici, come Orfeo, Anfionte e simili. La ragione di tutto questo si è perché vedendo troppo bene ciascuno auditore che almeno nelle parti più conosciute della terra non si parla in musica ma pienamente dalli uomini ordinarii, più si conforma con il concetto che si ha dei personaggi sopra umani il parlar in musica che com il concetto e manifesta notizia delli uomini dozzinali, perché essendo il ragionare armonico più alto, più maestrevole, più dolce e nobile dell'ordinario parlare, si attribuisce per un certo connaturale sentimento ai personaggi che hanno più del sublime e divino.... Anonimo: II corago o vero alcune osservazioni per metter bene in scena le composizioni drammatiche. (apud. Rosand, 1991, p. 244) 
preocupava nossos antepassados. "Pessoas não falam cantando"! Assim, o que é necessário para que uma convenção se torne aceita, é que ela funcione em termos cênicos. E quando ela funciona, é apenas a constância de seu uso que a transformará em convenção.

Portanto, resgatar essas convenções do passado (e transformá-las em convenções do presente, pelo menos enquanto ligadas à interpretação da música antiga) é tão importante para a execução do repertório dos séculos idos quanto resgatar a própria música da época. Sabe-se hoje que na música orquestral do barroco eram frequentes as evocações de tempestade, em que folhas de flandres eram sacudidas vigorosamente para imitar o tonitruar dos trovões, e outros recursos semelhantes criavam a ilusão de vento e de chuva. No Inverno, das "4 Estações", por exemplo, com o uso da madeira do arco atingindo diretamente as cordas, Vivaldi imita os dentes do protagonista, que batem uns nos outros em reação ao frio extremo, e usa passagens escalares rapidíssimas nas cordas para criar o efeito do vento - especificamente do Sirocco, vento quente, desagradável e violento, comum no norte da Itália. Escorregar no gelo também é reproduzido por meio de música, assim como as gotas de chuva tamborilando na janela.

O fato é que a plateia já ia para o concerto com uma expectativa em relação a este fenômeno: "vejamos como o Senhor Fulano irá lidar com a tempestade, desta vez". Ignorar essas convenções, olhar com desdém o uso de recursos extramusicais, como a folha de flandres, nos nossos dias frequentemente considerada apenas barulhenta e de mau-gosto, é não se dar conta do quanto tais recursos colaboravam para o resultado final da sonoridade pretendida, e o quanto eram fatores necessários para o total envolvimento da plateia na "viagem" proposta pelo compositor. Em relação à ópera, o mesmo era verdade. A plateia ia à apresentação com expectativas grandes em relação a momentos-padrão, para verificar, por exemplo, de que maneira a habilidade e a arte do autor e de seus intérpretes se refletiriam no tradicional dueto de amor. Em "O retorno de Ulisses à Pátria", por exemplo, parte da agudeza de Monteverdi reside justamente em adiar este momento tão esperado até o ultimíssimo segundo, e terminar a ópera imediatamente após, não no auge da exuberância, mas no auge da doçura. Depois 
de Monteverdi, o próprio conceito de tal "final feliz" passou a permear a história da ópera, e por sua influência direta, da opereta e do musical.

Muitas das convenções operísticas do século XIX nasceram bem antes, nos palcos da Itália seiscentista. Assim como na ópera posterior ao século XIX a “cena da morte"3 se torna quase que obrigatória, e é sempre um dos pontos altos da representação ${ }^{4}$, sendo um dos principais meios de que dispõem os ouvintes (e críticos) para julgarem a qualidade da execução e da composição, nos dois séculos anteriores é que se firmaram convenções como o travestimento, as cenas de loucura, o lamento pelo amor perdido, que irão sobreviver mesmo em obras bastante recentes.

Não há alma, por mais empedernida que seja, que consiga deixar de se enternecer ao presenciar a cena final da Traviata, de Verdi, que reúne, num só golpe de mestre, momentos de lamento expressivo ${ }^{5}$, loucura ${ }^{6}$ e finalmente, a ária de morte da heroína, talvez o cair de cortinas mais fulminante de toda a história da música. Mas poucos se dão conta da herança inegável que Verdi recebeu de seus antecessores.

Aliás, é curioso observar o desenvolvimento da cena de morte na ópera ocidental. Se no período barroco a morte aparece apenas relatada, ou anunciada, e são os efeitos da morte sobre os personagens principais que nos movem, aos poucos ela toma a cena e se desenrola diante de nossos olhos. Na ópera Euridice, de Peri e Rinuccini, encenada em 1600, em Florença, umas das passagens de maior impacto é o relato da morte de Eurídice, feito por Dafne. Segundo Richard Taruskin:

\footnotetext{
${ }^{3}$ Em seu site, a Universidade de Princeton oferece mais de 40 fotografias de cenas de morte em ópera que se tornaram famosas! (http://www.cs.princeton.edu/ san/death.html, acessado em 3/6/11)

${ }^{4}$ All of us know that in any Opera worth its salt the heroine at least has to die at the end and it is not uncommon if the hero and perhaps his rival die too. Knowing this irrefutable operistic trait, composers and their librettist have done a tremendous job providing their operas with some really great dead scenes. (Ventura, David em http://hubpages.com/hub/bizarre-deaths-in-the-opera, acessado em 3/6/11)

${ }^{5}$ Violetta protesta contra o destino, que a faz morrer tão jovem, com tanta vida e amor pela frente.

${ }^{6}$ Já em seu leito de morte, a cortesã encontra forças para pedir à sua querida Annina que Ihe dê o casaco, para irem à igreja, denotando claramente um estado delirante de percepção da realidade.
} 
A primeira coisa a notar é o rigor com que o compositor repele qualquer tentação de sucumbir às imagens do texto, embora este esteja recheado de oportunidades para a pintura de palavras -- o fluir da água, o murmúrio da água, luz, escuridão, cantando, dançando, para não falar sobre a picada da serpente. Nenhuma dessas imagens é pintada em tons. Não sobra uma gota de espírito, nada que possa suscitar um sorriso de reconhecimento. Em vez disso, o contraste afetivo brutal é transmitido através dos análogos musicais do discurso e do gestual retóricos. Quando, por exemplo, Dafne descreve o suor frio que salpicava o rosto de Eurídice e emaranhava seus cabelos durante a agonia da morte, a música se preocupa, não com o objeto descrito, mas sim com a emoção daquele que descreve, transmitida pela chocante falsa relação entre a voz e o baixo. O momento da morte de Eurídice é descrito com um horror ainda maior, mais frio: as palavras I bei Sembianti ("suas belas feições") são enfatizadas com ironia terrível, utilizando as harmonias mais feias que o compositor poderia conceber: uma tríade aumentada, seguida por uma flagrante contradição harmônica entre a voz (em Si bemol) e o acompanhamento (uma tríade de Mi maior), "resolvida" por um salto "proibido" de quinta diminuta descendente 7 . (Taruskin, 2010, p. 829830)

No Orfeo posterior, de Monteverdi (de 1607), a Mensageira, quebrando a benigna paz pastoral do mundo do protagonista e de seus amigos, traz as terríveis notícias da morte de Eurídice com dissonâncias de gelar o sangue. Mas em nenhum dos dois casos, nós presenciamos o momento exato da morte de Eurídice. Em Monteverdi, é a exposição das emoções cruas em tempo real que é explorada

\footnotetext{
7 The first thing to notice is the rigor with which the composer has spurned every temptation of the text's imagery, jam-packed though it is with opportunities for word painting - flowing water, murmuring water, light, dark, singing, dancing, to say nothing the serpent's bite. Not one of these images is painted in tones. There is nothing left of wit, nothing to bring a smile of recognition. Instead, the brutal affective contrast is transmitted through the musical analogues of rhetorical delivery and gesticulation. When, for example, Daphne describes the cold sweat that bespattered Eurydice's face and matted her hair during the death throes, the music is concerned not with the object described but rather with the emotion of the describer, conveyed in shocking false relation between the voice and the bass. The moment of Eurydice's death is described with even greater, colder horror: the words I bei sembianti ("her beautiful features") are set with hideous irony, using the ugliest harmonies the composer could devise - an augmented triad followed by a blatant harmonic contradiction between voice (on B-flat) and accompaniment (an E-major triad), "resolved" through a descent by a "forbidden " diminished fifth. (Taruskin, Richard. Music from the Earliest Notations to the Sixteenth Century. The Oxford History of Western Music). Oxford: Oxford University Press, 2010, p. 829-830)
} 
ao máximo. Em seu desenvolvimento, a ópera do século XIX irá procurar não mais apenas a crueza das emoções, mas também, ou até principalmente, a crueza dos fatos: a própria morte, representada em cena com requintes de sofisticação. A representação do instante em que se esvai a vida, e a riqueza e originalidade de métodos causadores de morte se tornam um autêntico desafio. As plateias irão testemunhar mortes por emparedamento, apunhalamento, enforcamento, tuberculose, armas de fogo, flechadas, envenenamentos variados (numa das mortes mais estranhas, Adriana Lecouvreur, a heroína da ópera de Cilea, falece após cheirar violetas envenenadas!), até mesmo por derretimento ${ }^{8}$ !

Mas a ópera não vive apenas da morte. Outras convenções comuns no gênero se estabeleceram nos seus primórdios: cenas de evocação e operações de magia, as aparições, os oráculos, as preces (preghieri) ${ }^{9}$, vingança, loucura, erro de identidade, lamentos, irão se refletir e desenvolver na ópera ocidental de nacionalidades diversas. Se na sua manifestação cômica predominam as situações de travestimento e erros de identidade (não há como não pensar nas Bodas de Fígaro, de Mozart, que leva ao paroxismo tais possibilidades), nas óperas dramáticas predominam as cenas de ciúme, vingança e desespero, e os Lamentos que refletem a dor da perda do amor ou de uma vida sem preocupações. Não é de se surpreender que, numa ópera inteiramente em tom maior (ainda as Bodas de Fígaro), a única ária em tom menor seja o sentido e belo lamento de Barbarina pela perda do broche (uma litania pela perda da inocência, talvez?)

Em sua gênese aristocrática, no ambiente florentino e mantovano surge, com a pungência própria dos solilóquios trágicos, o Lamento. Cena apropriada para momentos de ápice emocional e oportunidade de acesso à subjetividade da heroína (os heróis se lamentavam com menor frequência), os lamentos de cunho trágico eram ocasião apropriada para provocar reações catárticas no espectador e jamais seriam excluídos dos palcos de ópera, como vimos acima.

Como marco inicial da criação do subgênero literário-musical, conservouse até hoje o Lamento d'Arianna, único trecho que restou da ópera homônima de

${ }^{8}$ Em Snegourochka, de Rimsky Korsakov, a heroína é feita de neve, e derrete aos raios do sol.

${ }^{9}$ Fabbri, 2003, p. 89. 
Claudio Monteverdi (1567-1643) e Otavio Rinuccini, estreada em 1608 na corte de Mântua. No frontispício do libreto que sobreviveu em sua íntegra, lê-se: L'Arianna: Tragedia Rappresentata in Musica. Podemos compreender, a partir do título, a intenção do poeta em afiliar sua obra ao gênero alto e nobre da tragédia. Se as primeiras investidas na criação da ópera alinharam-na à tradição pastoril da tragicomédia, buscando em Guarini e Tasso fonte de inspiração poética, com L'Arianna, Rinuccini e Monteverdi tentaram contrapor ao ambiente baixo, povoado por pescadores e soldados da ilha de Naxos, o ambiente sublime da corte de Teseu e Ariadne. As linguagens de cada personagem traduzem a origem de sua linhagem, grave e altiva dentre os nobres, graças a sua natureza pública principesca, ou leve e frívola, ambientada no trabalho e nas recreações populares. ${ }^{10}$ Vejamos a entrada do coro de Soldados em que louvam Teseu por sair invicto do labirinto onde acabara de matar o Minotauro: $\mathrm{CORO}^{11}$

Se d'Ismeno in su la riva, $\mathrm{A}$ per ornar d'Alcide i vanti, B fa sentir celesti canti B nobil suon di cetra argiva, $\mathrm{A}$

Non fia già che muta Atene $C$ del buon Re taccia gli allori: D canteran cigni canori, D canteran ninfe e sirene. C

E diran ch'invitto e forte $E$ lasciò spento il mostro fero, $\mathrm{F}$ e che fuor del rio sentiero $F$ per uscir trovò le porte. $\mathrm{E}$ [...]
CORO

Se de Ismeno sobre a margem, Para ornar de Alcide as glórias. Faz ouvir celestes cantos Nobre som de cítara argiva,

Não será já que muda Atenas Do bom Rei cala os louros: Cantarão cisnes canoros, Cantarão ninfas e sereias.

E dirão que invicto e forte Deixou extinto o monstro fero, E que fora da cruel vereda Para sair encontrou as portas. ${ }^{12}$

Dada a perda irreparável da música de Arianna, só nos resta imaginar que tipo de composição Monteverdi teria utilizado para tais versos. Como muitos outros experimentos da época, o ambiente da Arcádia silvestre da tragicomédia é aqui transferido para cenário litorâneo, com seus personagens e mitos típicos. Os

\footnotetext{
${ }^{10}$ Estas classificações soam para o leitor contemporâneo como classistas e preconceituosas. Mas devemos exercitar um pouco o olhar do antropólogo para não impormos preconceitos anacrônicos a categorias já estabelecidas por Aristóteles em sua Poética, com quem, desde então, a história da literatura ocidental entrou em incansável debate.

${ }^{11}$ As letras se referem às rimas.

12 Tradução elaborada em conjunto com Ariadne Melchioretto, no Grupo de Pesquisa em Música Ántiga (UFPR/CNPq).
} 
soldados e pescadores que dividem a cena com os nobres príncipes de Naxos correspondem, na ópera perdida de Monteverdi, aos personagens pastoris representados em Orfeo e nas principais obras dramático-musicais da época. Típicos da poesia mélica do poeta seiscentista Gabriello Chiabrera (1552-1638), os versos ottonari (oito sílabas) em estrofes rimadas foram muito utilizados para momentos corais encantadores ou em prazerosas árias de pastores, como nas famosas canções de Striggio/Monteverdi em Orfeo: Vi ricorda, o Boschi ombrosi ou Ecco pur ch'a voi ritorno. Podemos imaginar que a ária dos Soldados poderia ter sonoridade bastante semelhante.

A este canto alegre e laudatório, percebemos de imediato o contraste com o tom intensamente patético do lamento de Ariadne. Seu discurso sublime reproduz uma série de topoi da retórica da mulher em situação de desamparo e abandono. Como no mito de Eurídice e na estória de Dido, Ariadne também não poderá consumar os votos de matrimônio com seu cobiçado amante Teseu, e como a temível Medéia, será responsável pela morte do irmão e consequente negação e expulsão da casa paterna. Sem lar, sem reino e sem a redenção de um desejado casamento, o lamento de Ariadne de Rinuccini/Monterverdi desvela o momento de maior intimidade da personagem. Este é um ponto de suspensão da ação, e através da descomposta narrativa lírica se revela o destino trágico da heroína: ao despertar sozinha à beira da praia, percebe que sua cega entrega ao amor de Teseu fora em vão - não lhe resta outra escolha que o consolo da morte. Grita Ariadne: "Deixai-me morrer, deixai-me morrer,"13 e logo a seguir suplica, enternecida, a volta de seu amado: "Retorna, Teseu meu, retorna, Teseu, ó Deus!" 14 Logo, é tomada por perturbada fúria e condena Teseu à pior das mortes: “Ai, ainda assim não responde! ai, mais que uma serpente, é surdo a meus lamentos! / Ó nuvens, ó redemoinhos, ó ventos, / afogai-o sob aquelas ondas! correi, monstros e baleias, e seus membros imundos espalhai no abismo profundo!"15 Para a representação do discurso patético e desorientado e a

\footnotetext{
${ }^{13}$ Lasciatemi morire!

${ }^{14}$ Volgiti, Teseu mio, volgiti, Teseu, O Dio!

${ }^{15}$ Ahi, che non pur rispondi! ahi, che più d'aspe è sordo a' miei lamenti!O nembri, O turbi, O venti, sommergetelo voi dentr'a quell'onde! correte, orche e balene, e delle membra immonde empiete le voragini profonde!
} 
expressão de sentimentos tão intensos e contraditórios, Monteverdi utilizaria o mais apropriado recurso de composição, recentemente inventado, o recitativo. A escrita de Monteverdi, aguda e precisa na imitação retórica do discurso patético de Rinuccini faz com que cada insinuação sutil de emoções contraditórias seja perfeitamente delineada pelas figurações rítmicas e melódicas criadas pelo compositor. Nenhum detalhe dos estados psíquicos extremos da personagem escapa ao "divino Monteverdi," e o resultado é um retrato minucioso da alma feminina em momento de profunda dor e comoção. A seguir (vide Ex. 1) podemos observar a escrita meticulosa de Monteverdi para representar um dos momentos da mais extrema perturbação psíquica de Ariadne: ${ }^{16}$

Exemplo 1 - Monteverdi, Claudio. Trecho do Lamento de Arianna. Transcrição da versão em facsímile de 1623, sem número de compasso.
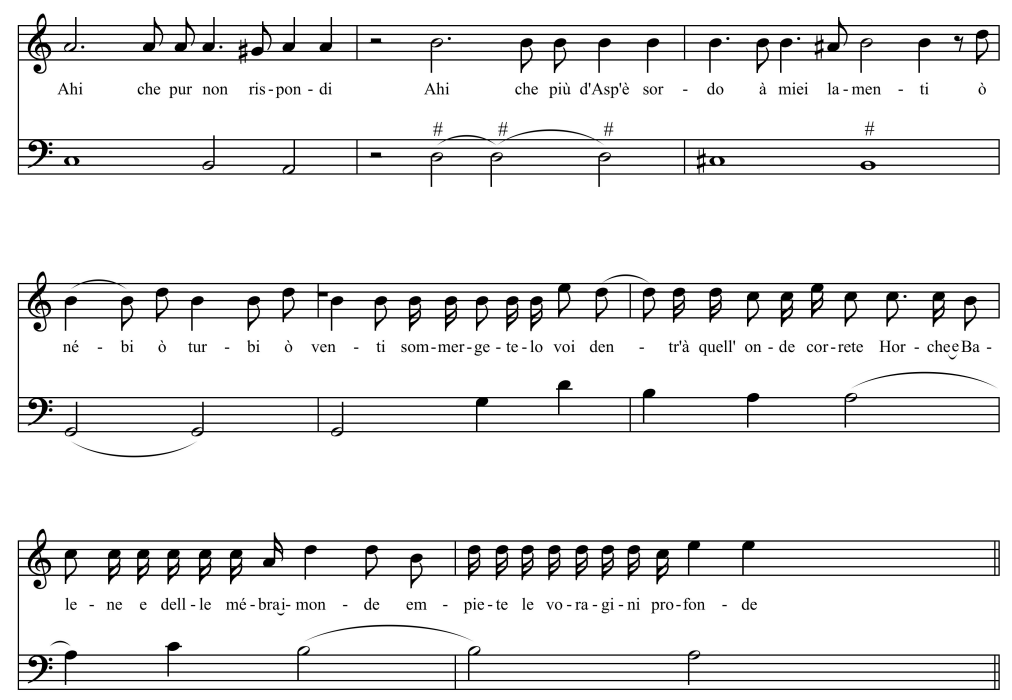

$\mathrm{Ai}$, ainda assim não responde! / $\mathrm{Ai}$, mais que uma serpente, é surdo a meus lamentos! / Ó nuvens, ó redemoinhos, ó ventos, / Afogai-nos sob aquelas ondas! / Correi, orcas e baleias, E dos membros imundos / Enchei os abismos profundos.

Para discursos com tal conteúdo catártico, em que a importância da fala se sobrepunha à do canto, uma atriz de grande poder dramático seria contratada para o papel: a personagem foi interpretada por uma famosa atriz de commedia

16 Trecho retirado do link: http://www.wwnorton.com/college/music/hill/Scores/W01\%20 Claudio\%20Monteverdi, Lamento\%20d\%27Arianna.pdf; acessado em 11/06/2011. 
del arte, Virginia Andreini, que segundo relatos da época, levou às lágrimas todas as mulheres da numerosíssima plateia.

L'Arianna, antes de se perder no passado, seria reapresentada em Veneza no Teatro S. Moisè, em 1640, já em contexto completamente diverso de seu nascimento em ambiente nobre da corte de Mântua. Trinta e dois anos depois de sua estréia, L'Arianna conviveria com uma audiência muito diferente da que presenciara a atuação da jovem e engenhosa atriz de 1608.

Monteverdi, então morando em Veneza, influenciaria diretamente os autores do dramma per musica, como Francesco Cavalli (1602-1676), seu aluno e herdeiro da refinada capacidade de interpretar musicalmente as nuances da poesia dramática e de representar as profundezas psíquicas dos personagens. Autor de mais de 40 óperas, Cavalli obteria pleno reconhecimento com Giasone, obra que atingiu popularidade extraordinária na época. Baseado em libreto de Andrea Cicognini, o texto se destaca dos libretos contemporâneos pela variedade e sofisticação poética, assim como pela mistura de personagens sérios e cômicos em seu enredo.

Dentre as cenas que se tornaram mais famosas está a de Medea, e a tenebrosa invocação dos espíritos do mundo subterrâneo (vide Ex. 2). Esta cena é um verdadeiro tour de force poético graças à escolha de diferentes metros, com intenções dramáticas agudíssimas, fornecendo a Cavalli ocasião para criar uma orquestração eletrizante, prenunciando a música mais eficaz para cenas de terror do cinema moderno. Medea, personagem de origens trágicas, nos revela toda sua fúria contra Jasão, o herói traidor, explodindo em versos sdrucciolli (proparoxítonas): Dell'antro magico, Istridenti cardini, /il varco apritemi [...]Sull'ara orribile /del lago stigio / i fochi splendino [...] (Do antro mágico /estridentes aldravas, /abram-me passagem. [...]Sobre o horrível altar /do lago infernal / resplandeçam as chamas [...]).

A ópera se encerra com uma delicada e sensual cena de amor; Cavalli inclui mais dois personagens no formato já estabelecido do dueto de amor, numa antecipação quase clarividente dos finais mozartianos (Ex. 3). 
Exemplo 2 - Cavalli, Francesco. Giasone. Ato I, cena 11. In: Rosand, compasso 170, p. 47, s/ data. Cena de invocação dos espíritos de Medea.
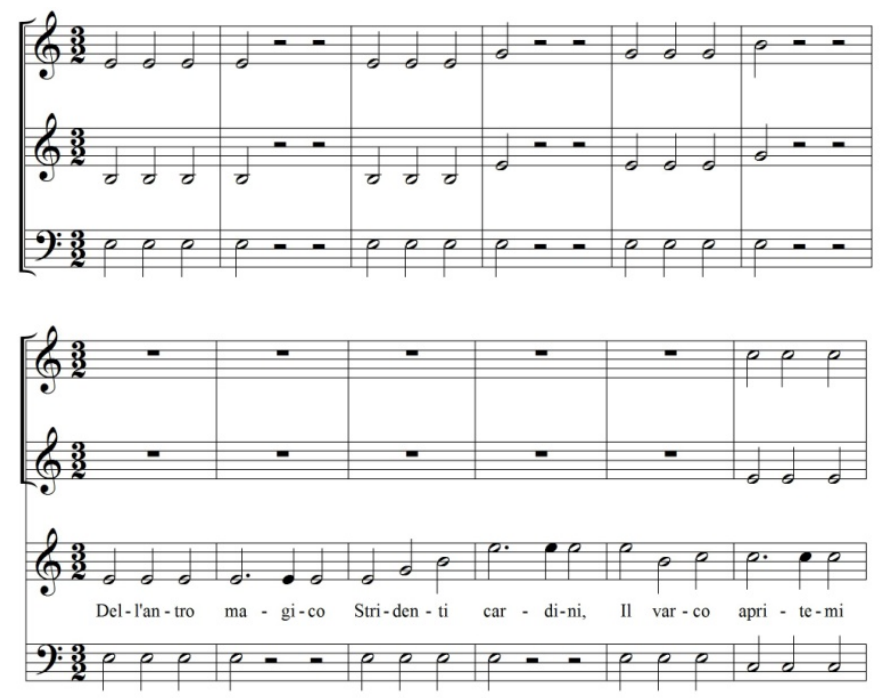

Exemplo 3 - Cavalli, Francesco. Giasone. Ato III, cena 21. In: Rosand, compasso 170, p. 302, s/ data. Cena final.

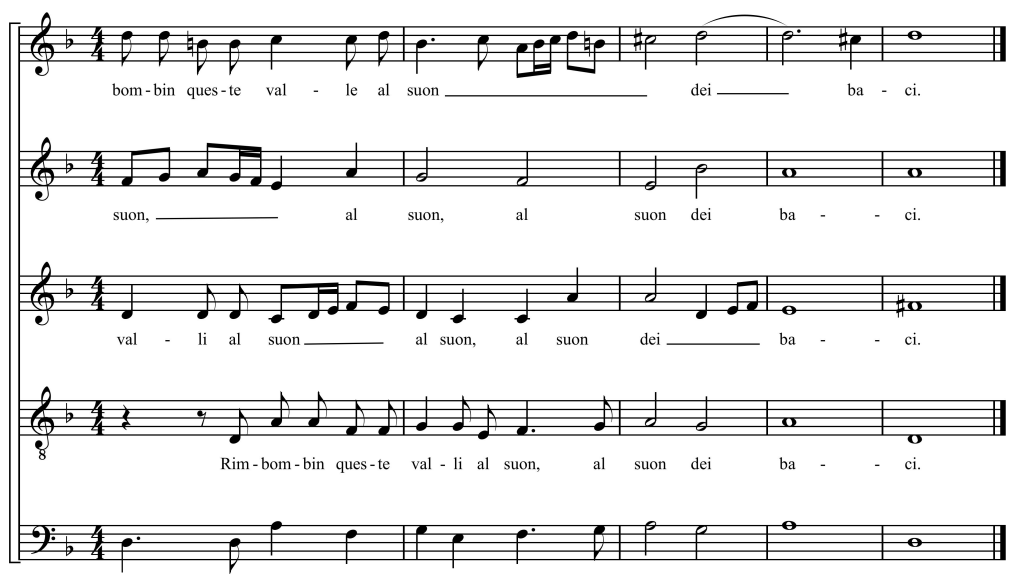

Considerada um exemplo perfeito de escrita musical virtuosística, a cena das Bodas de Figaro ("Riconosci in questo amplesso") em que o conde, Figaro, Susanna, Marcellina, D. Bartolo, D. Curzio cantam ao mesmo tempo emoções distintas, sem perderem sua própria personalidade ou diluírem o sentimento proposto, mantém ainda assim uma coerência que permite ao ouvinte identificar cada voz individualmente enquanto ouve a peça como um todo. Depois de Mozart, o recurso continuou a ser utilizado amplamente na música vocal 
operística: Verdi no famoso quarteto do Rigoletto (1851). Strauss em Die Fledermaus (1874), o sexteto vocal "Chi mi frena in tal momento" de Donizetti, na já mencionada Lucia de Lammermoor (1839), o quinteto de Wagner em Die Meistersinger (1868), o quarteto de Puccini em La Bohème (1896), exemplos não faltam. Reunir várias vozes transmitindo sentimentos semelhantes, diferentes ou até mesmo conflitantes não é ideia nova, mas é nos palcos venezianos do Seiscentos que se insinua pela primeira vez em ópera e acabará se cristalizando como hábito.

A dívida da ópera com os séculos que antecederam sua cristalização é bem evidente, se nos debruçamos sobre obras bem distintas. A grande ária de loucura (II dolce suono) de Lucia di Lammermoor, personagem da ópera homônima de Donizetti, que acaba por cometer assassinato ainda vestida de noiva, encontra raízes cênicas óbvias em mestres do passado. Não bastasse o texto eloquente, as variações de andamento que denotam a fuga do racional, os melismas desabridos, há ainda o recurso curioso (e bem calcado nos efeitos teatrais tão populares no barroco) a uma harmônica de vidro, com seu som fantasmagórico e inconsútil. Esse efeito, que teria sido recebido com entusiasmo irrefreado nos séculos anteriores, acaba por se perder nos séculos posteriores. Durante a quase totalidade das apresentações desta ópera no século XX, a harmônica de vidro, com sua sonoridade tão peculiar, acabou sendo substituída pela flauta, que tem um timbre que pode ser considerado mais "bonito", mas certamente menos apropriado para o clima espectral e delirante da orquestração original. Não à toa, foi nos últimos anos, em que se busca resgatar a interpretação histórica da música, que a harmônica de vidro voltou à cena (conferir a bela interpretação de Natalie Dessay como Lucia, na versão do Metropolitan Opera de 2007). ${ }^{17}$

Para qualquer um que conheça bem a música do Barroco, ao ouvir a tresloucada Lucia, é difícil não pensar numa das mais poderosas obras de Purcell, considerada por vários musicólogos como a melhor das suas canções para teatro: From Rosy Bowers, composta durante o período de sua doença fatal. Para esta

\footnotetext{
${ }^{17}$ http://www.youtube.com/watch?v=NYm7oJXVeks, acessado em 03/06/2011
} 
charada musical (uma ária de loucura cantada por uma mulher que não é louca!), Purcell consegue criar uma engenhosa "cantata de desequilíbrio", em que um fluxo ensandecido de emoções é vividamente retratado em suas cinco seções, admiravelmente conectadas. O mais curioso é que a intenção da música (se a consideramos inserida em seu contexto) não é séria como parece. Retrata uma loucura apenas fingida pela protagonista, a fútil Altisidora, numa tentativa de seduzir Don Quixote e afastá-lo de sua Dulcinéia. A loucura fingida, tão bem explorada por Purcell, tem suas origens justamente na Itália do Seiscentos.

La finta pazza, de Francesco Sacrati, o primeiro grande hit operístico, abriu as portas do Teatro Novissimo no carnaval de 1641, pondo em cena a soprano Anna Renzi, “jovem donzela tão talentosa como atriz quanto excelente na música [...]." Esta ópera reinventa, na maneira livre e iconoclasta dos libretistas venezianos, o mito de Aquiles e Deidamia, e nesta obra praticamente ignorada ${ }^{18}$ pelas platéias de hoje, conhecemos a primeira cena de loucura em ópera. Por ser finta (fingida), a loucura de Deidamia tem caráter cômico, revelando o parentesco muito próximo entre os primórdios da ópera e a commedia dell'arte. Deidamia se faz de louca para dissuadir o amado de partir para a guerra. Como outros personagens que representam a loucura em ópera, eles tomam emprestado da commedia "falas despropositais, alucinações, palavreado excessivo, e exuberância nas canções". ${ }^{19}$ As convenções herdadas diretamente da commedia se revelam também nas confusões criadas pelas trocas de gêneros altos e baixos; ou seja, personagens altos (princesas, como no caso de Deidamia) tomam emprestada a linguagem baixa pouco apropriada à sua estirpe. A falsa louca Deidamia atropela o espectador com seu discurso excessivo, sua alucinação fingida, seu jogo de troca de gênero, súbitas quebras de desenvolvimento lógico e desvio de raciocínio. No ato II, cena 9 (vide Ex. 4), Deidamia tenta se fazer passar por comandante e ordena que seus (falsos) guerreiros tomem as armas. A música de Sacrati

\footnotetext{
18 Neste caso, a ignorância não pode ser imputada às plateias e nem aos músicos. 0 musicólogo italiano, Lorenzo Bianconi, tem acesso à obra, mas segundo informação recebida informalmente por $\mathrm{E}$. Rosand, a família a qual pertence a partitura proíbe a disponibilização da mesma.

${ }^{19}$ Fabbri, 2003, p.109.
} 
acompanha a representação da representação, e se utiliza da convenção teorizada e fixada por Monteverdi para a imitação da ira, o stile concitato:

Exemplo 4 - Sacrati, Francesco. La finta pazza, Ato II, Cena 9 (sem número de compasso, in Rosand, 1991, p. 597).

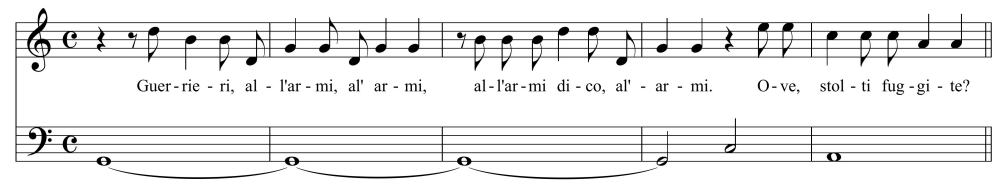

Guerreiros, às armas; / às armas, vos digo, às armas. / Para onde, tolos, fugis?

La finta pazza brinca o tempo todo com o jogo da representação, da dita suspension of desbelief, provocando o espectador com a questão crucial que angustiou os criadores da ópera e até hoje fundamenta os argumentos dos detratores do gênero. Seria possível "imitar" - no sentido aristotélico do termo ações de personagens que não falam, mas cantam? Deidamia diverte e até zomba do espectador com um vaivém exuberante de ilusões. O público sabe que Deidamia finge, a própria Deidamia sabe que sua loucura é fingida, mas os personagens em cena acreditam que a louca princesa delira e os chama para uma guerra inexistente. Dela fogem, e Deidamia, num falso tom de decepção, após o trompetear em sol maior, suspende a frase (pausa de semínima) e conclui, em lá menor, com uma queixa pela fuga de seus soldados. Podemos facilmente imaginar soluções dramáticas para a pequena cena, na qual os "soldados" de Deidamia fogem correndo para todos os lados, e deixam-na com expressão de espanto e decepção, sozinha no palco, fingindo sua surpresa. Neste momento, o jogo de ilusões se multiplica intensificando o caráter cômico da cena, pois naquele exato momento, a personagem poderia romper a farsa, já que o público sabe que a loucura é falsa. Continuando, sozinha, a fingir, Deidamia convida o público a jogar com ela e perder-se no labirinto das ilusões, do make-belief, um dos ingredientes primordiais de qualquer espetáculo, e principalmente, da joveníssima ópera. 0 texto e música de La finta pazza nos permitem adivinhar as excelentes qualidades de Anna Renzi como cantora e atriz, que mais adiante levará seu virtuosismo a um ápice, ao recusar-se a cantar (ou falar?!), optando, já que nela ninguém acredita, 
pelo mutismo, e passando a representar (ou fingir?!) sem fala nem canto, mas com gestos:

A stride, quiete, dunque, ad intendersi a cenni, alla muta, alla muta, pronta man, occhio presto, quel che diria la lingua, esprima il gesto.
Fiquemos quietos, então, e entendamo-nos através de sinais como mudos, como mudos, prontas mãos, olhos rápidos, o que diria a língua, que diga o gesto. ${ }^{20}$

La finta pazza pode ser vista como emblema de uma das questões mais caras e dolorosas do barroco, ou seja, a percepção do mundo como teatro, ou como diria Calderón, da fugacidade da vida, que não passa de um sonho, e das aparências, sempre enganadoras. Todas as experimentações na ópera de Strozzi e Sacrati assim como na de tantos outros autores do período revelam as ansiedades e instabilidade de uma época em que a profusão do gesto exterior representa a perplexidade do homem diante de um vazio interior. Típico do teatro barroco é a perda dos limites entre realidade e aparência, dissimulação e equívoco, máscara e revelação. Um dos poetas mais influentes do período, Giambatista Marino (15691625), em seu vasto poema mitológico, L'Adone explora com o gesto excessivo, tipicamente barroco, surpreendentes imagens e inumeráveis representações metafóricas do mundo como teatro: tanto tesor, tanto splendor disserra, / che sembra appunto il ciel calato in terra ${ }^{21}$ (que tesouro, que esplendor descerra, / que parece justamente o céu descido à terra).

Revisitar as convenções vocais do Seiscentos italiano, assim como as complexidades estéticas e filosóficas em que estavam inseridas, não somente nos esclarece a respeito de gestos musicais que se tornaram praticamente obrigatórios nos períodos subsequentes, como nos permite, enquanto músicos, interpretar este repertório com uma percepção mais límpida de sua complexidade, trazendo à tona uma miríade de significados dos quais podemos ousar nos apossar.

\footnotetext{
20 Tradução elaborada em conjunto com Viviane Kubo, no Grupo de Pesquisa em Música Antiga (UFPR/CNPq).

${ }^{21}$ Trecho retirado de http://www.letteraturaitaliana.net/pdf/Volume_6/t330.pdf; acesso em $12 / 06 / 2011$.
} 


\section{Referências}

ANGELINI, Franca. // teatro barroco. Roma: Editori Laterza, 1982. Terceira edição. AUSTIN, William. New looks at Italian Opera: essays in honor of Donald J. Grout, Santa Barbara: Greenwood Press, 1976.

FABBRI, Paolo. Il secolo cantante: Per una storia del libretto d'opera in Italia nel Seicento. Roma: Bulzoni editore, 2003. Segunda edição.

HENDERSON, William James. Some Forerunners of Italian Opera, 1911 Toronto: Robarts, University of Toronto, Project Gutemberg.

LA VIA, Stefano. Poesia per musica e musica per poesia. Milão: Editora Carocci, 2006.

ROSAND, Ellen. Opera in Seventeenth-Century Venice: The Creation of a Genre Berkeley: University of California Press, 1991.

ROSENFELD, Anatol. O teatro épico. São Paulo: Editora Perspectiva, 2006. Terceira edição.

ROTONDI, Joseph Emilio. Literary and musical aspects of Roman opera, 16001650. Philadelphia: University of Pennsylvania, 1959.

SNOWMAN, Daniel. The gilded stage - A social history of opera, Londres: Atlantic Books, 2009.

STERNFELD, Frederick William, The Birth of Opera. Clarendon Press, 1995.

TARUSKIN, Richard. Music from the Earliest Notations to the Sixteenth Century (The Oxford History of Western Music). Oxford: Oxford University Press, 2010. 